\title{
Molecular tectonics: design and generation of charge assisted $H$ bonded hybrid molecular networks based on amidinium cations and thio- or isothio-cyanatometallates
}

\author{
${ }_{5}$ Gabriela Marinescu $^{\text {a,b,c }}{ }^{\text {, Sylvie Ferlay }}{ }^{*}$, Nathalie Kyritsakas ${ }^{\mathfrak{c}}$ and Mir Wais Hosseini ${ }^{{ }^{*}}$ \\ Received (in XXX, XXX) 1st January 2007, Accepted 1st January 2007 \\ First published on the web 1st January 2007 \\ DOI: $10.1039 / b 000000 x$
}

Upon combining the bis amidinium dication $1-2 \mathrm{H}^{+}$with thiocyanatometallates $\mathrm{M}(\mathrm{SCN}) 4^{2-}(\mathrm{M}=\mathrm{Pd}$, ${ }_{10} \mathrm{Hg}$ ) or isothiocyanatometallates $\mathrm{Cu}(\mathrm{NCS})_{4}{ }^{2-}$ anions behaving as $\mathrm{H}$-bond donor and acceptors respectively, three new hybrid molecular networks have been obtained in the crystalline phase and structurally characterized by X-ray diffraction on single crystals. Whereas for the combination of tecton $1-2 \mathrm{H}^{+}$and both $\mathrm{Pd}(\mathrm{SCN})_{4}{ }^{2-}$ and $\mathrm{Hg}(\mathrm{SCN})_{4}{ }^{2-}$ anions analogous $1-\mathrm{D}$ H-bonded networks were observed, for $\mathrm{Cu}(\mathrm{NCS})_{4}{ }^{2-}$ anion a 2-D network was obtained. Based on structural features of both 15 components, the formation of the two types of networks is discussed.

\section{Introduction}

The design and generation of hybrid molecular networks ${ }^{1}$ combining organic and metal complexes are attracting considerable interest over the last years. Among various ${ }_{20}$ possible design principles, the most used one is based on the use of the first coordination sphere through direct interconnection between organic building blocks or tectons ${ }^{2,3}$ and metal centres. This strategy affords coordination networks or MOFs. ${ }^{4}$ An alternative approach consists in exploiting 25 specific interactions at the second coordination sphere around metal centres. ${ }^{3,5}$ In particular, using simultaneously directional H-bonding and charge-charge electrostatic interactions, one may generate robust networks. The viability of this approach has been demonstrated.$^{6-8}$ We have previously 30 illustrated this strategy by combining bis amidinium based tectons such as $\mathbf{1 - 2} \mathrm{H}^{+}$(Scheme) and its analogues with a variety of cyanometallate $\mathrm{M}(\mathrm{CN})_{\mathrm{n}}{ }^{\mathrm{m}-}$ anions $(\mathrm{M}=\mathrm{Au}$ or $\mathrm{Ag}(\mathrm{n}$ $=2, \mathrm{~m}=1) ; \mathrm{M}=\mathrm{Ni}, \mathrm{Pd}, \operatorname{Pt}(\mathrm{n}=4, \mathrm{~m}=2) ; \mathrm{M}=\mathrm{Fe}, \mathrm{Co}, \mathrm{Cr}(\mathrm{n}$ $=6, \mathrm{~m}=3)$ and $\mathrm{M}=\mathrm{Fe}, \mathrm{Ru}(\mathrm{n}=6, \mathrm{~m}=4)$ offering linear 35 square planar and octahedral geometries respectively. ${ }^{6}$ Furthermore, we have also reported the formation $\mathrm{H}$-bonded networks between cationic tectons and oxalatometallates anions. ${ }^{9}$

Scheme

Pursuing our effort along these lines, we have extended our investigation to thiocyanatometallates $\mathrm{M}(\mathrm{SCN})_{4}{ }^{2-}$ and isothiocyanatometallates $\mathrm{Cu}(\mathrm{NCS}){ }_{4}{ }^{2-}$ anions, which present 45 interesting geometrical and structural features. Other examples of molecular networks based on the formation of D$\mathrm{H} \cdots \mathrm{S}$ or $\mathrm{D}-\mathrm{H} \cdots \mathrm{N}$ hydrogen bonds along with $\mathrm{S} \cdots \mathrm{S}$ interactions have been reported in the litterature. ${ }^{10}$

Here we report our studies on the formation of three new 1-
${ }_{50} \mathrm{D}$ and 2-D charge assisted $\mathrm{H}$-bonded networks generated upon combination of the dicationic tecton $1-2 \mathrm{H}^{+}$and $\mathrm{M}(\mathrm{SCN}) 4^{2-}(\mathrm{M}$ $=\mathrm{Pd}, \mathrm{Hg})$ and $\mathrm{Cu}(\mathrm{NCS})_{4}{ }^{2-}$ anions.

\section{Results and discussion}

55 Molecular networks are periodic architectures generated by self-assembly processes between molecular tectons. ${ }^{1}$ Their design requires the fine tuning of the recognition events taking place between tectons. For charge assisted H-bond based networks, one needs to combine anionic (H-bond 60 acceptor) and cationic (H-bond donor) components. ${ }^{5}$ Thiocyanometallate and isothiocyanometallate anions have been targeted as H-bond acceptor partners because, when associated with metal centres, they display interesting coordination modes leading to a variety of possible H-bond ${ }_{65}$ patterns. Indeed, as shown in figure 1, depending on the nature of the metal, $\mathrm{SCN}^{-}$anion may bind to the metal through either thiocyanato (M-SCN) or isothiocyanato (M-NCS) coordination's mode. ${ }^{11}$ Although, owing to the non linear disposition of $\mathrm{M}, \mathrm{S}$ and $\mathrm{C}$ atoms, thiocyanometallate anions 70 differ from their cyanometallate analogues by size and by geometry, in terms of H-bonding, they behave in a similar fashion (Fig. 1). For isothiocyanometallate complexes, often unstable in solution and generated in situ, due to the presence of three free lone pairs on sulphur, although in terms of 75 coordination geometry they are similar to cyanometallate anions, as H-bond acceptors, they offer different possibilities.

Figure 1

80 In order to investigate these features, we have chosen to study the following stable conplexes : $\mathrm{Pd}(\mathrm{SCN})_{4}{ }^{2-}$ (square planar geometry around $\mathrm{Pd}$ centre), $\mathrm{Hg}(\mathrm{SCN})_{4}{ }^{2-}$ ( $\mathrm{Td}$ geometry for $\mathrm{Hg}$ 
cation) anions as thiocyanometallate species and $\mathrm{Cu}(\mathrm{NCS})_{4}{ }^{2-}$ (square planar geometry around $\mathrm{Cu}$ ) anion as isothiocyanometallate complex.

Taking into account both the charged and geometrical 5 characteristics of the above mentioned anions, the tecton 1$2 \mathrm{H}^{+}$appeared as the most appropriate candidate to obtain hybrid inorganic/organic networks. Indeed, the bisamidine $\mathbf{1}$ behaves as a dibase and thus may undergo double protonation leading to the dicationic tecton $\mathbf{1}-2 \mathrm{H}^{+}$(see scheme). The latter 10 offers two equivalent sets of two acidic hydrogen atoms on each face of the molecule and thus must behave as a tetra $\mathrm{H}$ bond donor. It is important to note that due to the difference in the $\mathrm{pK}_{\mathrm{a}}$ values between $\left[\mathrm{MX}_{4}\right]^{2-}(\mathrm{X}=\mathrm{NCS}$ or $\mathrm{SCN})$ anions and unprotonated $\mathbf{1}$, protons should be localised on the 15 nitrogen atoms of $\mathbf{1}$, offering the possibility of combining strong hydrogen bonds with electrostatic charge-charge interactions. Furthermore, the association of the dianionic complexes with the dicationic tecton $1-2 \mathrm{H}^{+}$, by ensuring charge compensation, would lead to the formation of neutral 20 networks. Finally, the use of rigid phenylene spacer connecting the two amidinium cycles at positions 1 and 4 imposes a distance of $c a 7 \AA$ between two acidic $\mathrm{N}$ atoms localized on the same face of the tecton. ${ }^{12}$ This structural features is important since it should control the mode of $\mathrm{H}$ 25 bonding with $\left[\mathrm{MX}_{4}\right]^{2-}$ anions. In principle, for the combination of $\mathbf{1}-2 \mathrm{H}^{+}$dication with tetrathiocyanide anions such as $\mathrm{M}(\mathrm{SCN})_{4}{ }^{2-}(\mathrm{M}=\mathrm{Pd}$ or $\mathrm{Hg})$, one would expect a dihapto mode of $\mathrm{H}$-bonding i.e. formation of two $\mathrm{H}$-bonds with same anion on the same face of the tecton leading to the 30 generation of a neutral 1-D network (Fig. 2a). This type of interactions and network's dimensionality have been previously demonstrated for $\left[\mathrm{MCN}_{4}\right]^{2-}(\mathrm{M}=\mathrm{Ni}, \mathrm{Pd}$ and $\mathrm{Pt})$ anions. ${ }^{6}$ However, for isothiocyanometallate such as $\mathrm{Cu}(\mathrm{NCS})_{4}{ }^{2-}$, owing to linear nature of the NCS- ligand and 35 the presence of three lone pairs on the sulphur atom capable of acting as H-bond acceptor (Fig. 1), one can not rule out a monohapto mode of H-bonding and thus the formation of a 2 D network (Fig. 2b).

Figure 2

The combination of $\mathbf{1 - 2 \mathrm { H } ^ { + }}$ with $\left[\mathrm{MX}_{4}\right]^{2-}(\mathrm{M}=\mathrm{Pd}, \mathrm{Hg} ; \mathrm{X}=$ $\mathrm{SCN}$, or $\mathrm{M}=\mathrm{Cu} ; \mathrm{X}=\mathrm{NCS}$ ) leads to the formation of crystalline materials, which were structurally characterised by ${ }_{45} \mathrm{X}$-ray diffraction on single crystals (see experimental section). In the case of $\mathrm{Hg}$ and $\mathrm{Pd}$ species, single crystals were obtained from an aqueous solution using a $1 / 1$ ratio of $1-2 \mathrm{H}^{+} /\left[\mathrm{MX}_{4}\right]^{2-}$, whereas in the case of $\mathrm{Cu}$ complex, a $1 / 1 / 2$ ratio of $\mathbf{1 -}$ $2 \mathrm{H}^{+} / \mathrm{Cu}^{2+} / \mathrm{NCS}^{-}$was used.

${ }_{50}$ For all three combinations, crystals are exclusively composed of $1-2 \mathrm{H}^{+}$dication and $\left[\mathrm{MX}_{4}\right]^{2-}$ dianion, no water molecules are present in the lattice implying that the cohesion of the crystal is ensured by the two components.

For the dication $1-2 \mathrm{H}^{+}$, in all three cases (Fig. 3-5), the 55 average $\mathrm{C}-\mathrm{N}$ distance of $c a 1.31 \AA$ and average N-C-N angle of $c a 121,5^{\circ}$ respectively are close to the average values observed fort $\left(1-2 \mathrm{H}^{+}, 2 \mathrm{Cl}^{-}\right)$salt $\left(1.31 \AA\right.$ and $\left.122.3^{\circ}\right){ }^{12}$ The two 6-member amidinium cycles adopts, as previously observed, a half chair conformation and are almost parallel 60 and coplanar but tilted with respect to the phenylene ring with the NCCC dihedral angle varying between $-48^{\circ}$ and $47^{\circ}$. The average distance of $c a 7 \AA$ between nitrogen atoms belonging to two amidinium units and localised on the same side of the molecule is almost the same as the one observed for $\left(1-2 \mathrm{H}^{+}\right.$, $\left.{ }_{65} 2 \mathrm{Cl}^{-}\right)$salt. ${ }^{12}$

For both $\mathrm{Pd}(\mathrm{SCN})_{4}{ }^{2-}$ (Fig. 3a) and $\mathrm{Hg}\left(\mathrm{SCN}_{4}{ }^{2-}\right.$ (Fig.4a), neutral 1-D H-bonded networks are formed by mutual interconnection of the dicationic and dianionic units through a dihapto mode of H-bonding taking place between acidic $\mathrm{N}-\mathrm{H}$ groups and $\mathrm{N}$ 70 atom of the thiocyanide ligand (Fig. 2a). The formed H-bonds are strong with the $\mathrm{N} \cdots \mathrm{N}$ distance in the range of $2.89 \AA$ and $2.96 \AA$ for the Pd complex and $2.85 \AA$ and $2.97 \AA$ for the $\mathrm{Hg}$ complex. The 1-D networks are arranged along the $c$ axis for $\mathrm{Hg}$ and along the $b$ axis for Pd. In the crystal, the 1-D 75 networks are packed in a parallel and antiparallel fashions along the $b$ axis for $\mathrm{Hg}$ (Fig. 4b) and along the $c$ axis for $\mathrm{Pd}$ (Fig. 3b). The distance between two consecutive metal centres within the 1 -D networks is $12.32 \AA(\mathrm{Pd})$ and $14.3(\mathrm{Hg}) \AA$, whereas, a distance of $7.16 \AA(\mathrm{Pd})$ and $7.18 \AA(\mathrm{Hg})$ is 80 observed for two metal centres belonging to two consecutive chains.

For the $\mathrm{Pd}(\mathrm{II})$ complex, the latter adopts a distorted square geometry with a Pd-S distances of 2.33(8) $\AA$. The S-C and $\mathrm{C} \equiv \mathrm{N}$ distance are in the range of $1.67(8)$ and 1.68(6) $\AA$ and ${ }_{85} 1.15(3) \AA$ and $1.16(3) \AA$ respectively. These distances are close to those generally observed for $\mathrm{Pd}(\mathrm{SCN})_{4}^{2-}$ anion. The SPdS angle varies between 89.3(2) and $106.0(8)^{\circ}$. As expected (Fig. 1b), the Pd-S bond is bend with PdSC angle varying between $105.5(8)^{\circ}$ and $106.1(8)^{\circ}$. The thiocyanide ${ }_{90}$ ligand is almost linear with the NCS angle of $176.5(2)^{\circ}$.

\section{Figure 3}

For the $\mathrm{Hg}$ (II) complex, the coordination geometry around the metal is a distorted tetrahedron with $\mathrm{Hg}-\mathrm{S}, \mathrm{S}-\mathrm{C}$ and $\mathrm{C} \equiv \mathrm{N}$ ${ }_{95}$ distances varying between $2.49(2) \AA$ - 2.57(17) $\AA, 1.65(6)$ $1.68(8) \AA$ and 1.14(8) $\AA-1.16(8) \AA$ respectively (Fig. 4). The $\mathrm{SHgS}$ angle varies between $97.9(5)^{\circ}$ and $116.2(7)^{\circ}$. The $\mathrm{Hg}-$ $\mathrm{SC}$ bond is bend, as expected, with the $\mathrm{HgSC}$ angle of varying between $101.4(6)^{\circ}$ and $104.8(2)^{\circ}$. The thiocyanide ligand is 100 almost linear with the NCS angle of varying between 174.3(6) and $177.7(6)^{\circ}$.

\section{Figure 4}

Unexpectedly, the isothiocyanocuprate anion $\mathrm{Cu}(\mathrm{NCS})_{4}{ }^{2-}$ 105 behaves differently (Fig. 5). Indeed, in that case, the dicationic and dianionic tectons are interconnected by $\mathrm{H}$ bonds through a tetra-monohapto mode of interaction between $\mathrm{NH}$ groups of $1-2 \mathrm{H}^{+}$and $\mathrm{S}$ atoms $(\mathrm{S} \cdots \mathrm{N}$ distances in the range of $3.32 \AA-3.40 \AA$ ). In average, this distance is compatible 110 with the one reported for other examples of $\mathrm{NH} \cdots \mathrm{S}$ H bond. ${ }^{13}$ As expected from the $c a 109^{\circ} \mathrm{S}$-lone pairs-S-C angle for the 
isothiocyanide ligand (Fig. 1c), the CS $\cdots \mathrm{N}$ fragment is bend with an angle varying between $83.6(17)^{\circ}$ and $91.3(18)^{\circ}$. Each dicationic tecton $1-2 \mathrm{H}^{+}$is $\mathrm{H}$-bonded to four $\mathrm{Cu}(\mathrm{NCS})_{4}{ }^{2-}$ anions (Fig. 5a) and each dianion is surrounded by four $1-2 \mathrm{H}^{+}$ 5 dications (Fig. 5b). Consequently, the mutual interconnection between anionic and cationic units leads to the formation of a neutral 2-D network (Fig. 5c). Consecutive sheets are packed along the $a$ axis.

The coordination geometry around the $\mathrm{Cu}(\mathrm{II})$ centre is a distorted tetrahedron with $\mathrm{Cu}-\mathrm{N}$ distance varying between 1.96(16) $\AA$ and 1.97(16) $\AA$. The $\mathrm{C} \equiv \mathrm{N}$ and $\mathrm{C}-\mathrm{S}$ distances are $151.16(2) \AA$, and $1.64(18) \AA$ respectively. The $\mathrm{N}-\mathrm{Cu}-\mathrm{N}$ angles varies between $89.6(7)^{\circ}$ and $90.4(7)^{\circ}$. The isothiocyanide ligand is nearly linear with the N-C-S angles of $177.7(16)^{\circ}$. The rather short $\mathrm{S} \cdots \mathrm{S}$ distance of $4.18 \AA$ implies some $\mathrm{S} \cdots \mathrm{S}$ interactions. Within the 2-D network, the $\mathrm{Cu}$ (II) centres form 20 a square with a $\mathrm{Cu} \cdots \mathrm{Cu}$ distance of $11.98 \AA$ (Fig. $5 \mathrm{c}$ ). The distance between two metal centres belonging to two consecutive sheets is $6.23 \AA$.

\section{Conclusions}

25 The combination of the dicationic tecton $1-2 \mathrm{H}^{+}$with thiocyanometallate $\left(\mathrm{Pd}(\mathrm{SCN})_{4}{ }^{2-}\right.$ and $\left.\mathrm{Hg}(\mathrm{SCN})_{4}{ }^{2-}\right)$ or isothiocyanometallate $\left(\mathrm{Cu}(\mathrm{NCS})_{4}{ }^{2-}\right)$ leads to the formation of three new neutral 1-D and 2-D periodic H-bonded infinite architectures. Based on structural features of the dicationic

30 and dianionic partners, the formation of 1-D networks through the establishment of $\mathrm{H}$-bonds of the dihapto type was predicted (Fig. 2a) and indeed observed both for $\mathrm{Pd}(\mathrm{SCN})_{4}^{2-}$ and $\left.\mathrm{Hg}(\mathrm{SCN})_{4}{ }^{2-}\right)$. However, the formation of the 2-D network resulting from the interconnection of $1-2 \mathrm{H}^{+}$dications and ${ }_{35} \mathrm{Cu}(\mathrm{NCS})_{4}{ }^{2-}$ dianions through a tetra monohapto mode on $\mathrm{H}$ bonding was not predicted but observed. This shift in the mode of H-bonding remains unclear and necessitate further studies.

The generation of H-bonded networks based on the 40 combination of tecton $1-2 \mathrm{H}^{+}$and analogues with a variety of hexathiocyanometallate and hexaisothiocyanometallate are currently under investigation.

\section{Experimental part}

\section{Materials}

The chemicals purchased from commercial sources (Strem, Lancaster Chemicals) were used without further purification. The organic bisamidinium tecton 1 was prepared as previously reported and was used as its hydrochloride salt. ${ }^{12}$ Both ${ }_{50}$ compounds $\mathrm{K}_{2}\left[\mathrm{Pd}(\mathrm{SCN})_{4}\right]^{14}$ and $\mathrm{K}_{2}\left[\mathrm{Hg}(\mathrm{SCN})_{4}\right]^{15}$ were prepared following published procedures.

\section{Crystallisation}

$\left(1-2 \mathrm{H}^{+},\left[\mathrm{Pd}(\mathrm{SCN})_{4}\right]^{2-}\right)$ : In a $8 \mathrm{~mm}$ diameter crystallization tube, upon slow diffusion through a ethanol layer $(1 \mathrm{~mL})$ of an 55 aqueous solution $(1 \mathrm{~mL})$ of $1-2 \mathrm{H}^{+}, 2 \mathrm{Cl}^{-}(7.6 \mathrm{mg}, 0.024 \mathrm{mmol})$ into an aqueous solution $(1 \mathrm{~mL})$ of $\mathrm{K}_{2}\left[\mathrm{Pd}(\mathrm{SCN})_{4}\right](10 \mathrm{mg}$, $0.024 \mathrm{mmol}), \quad$ red-orange single crystals $\left(\left[\mathrm{Pd}(\mathrm{SCN})_{4}\right]\left[\mathrm{C}_{14} \mathrm{H}_{20} \mathrm{~N}_{4}\right]\right)$ were obtained in quantitative yield at room temperature after several days. Anal.: Calcd. for ${ }_{60} \mathrm{C}_{18} \mathrm{H}_{20} \mathrm{~N}_{8} \mathrm{PdS}_{4}$ : C, 37.04; H, 3.43; N, 19.20\%. Found: C, $35.11 ; \mathrm{H}, 3.43 ; \mathrm{N}, 19.23 \%$. IR data $\left(\mathrm{KBr} /\right.$ pellet, $\left.\mathrm{cm}^{-1}\right): 3167$, 3015, 2098, 1648, 1607, 1540, 1506, 1455, 1370, 1311, 1308, $1275,1199,803,670$ and 505 .

${ }_{65}\left(\mathbf{1}-2 \mathrm{H}+,\left[\mathrm{Hg}(\mathrm{SCN})_{4}\right]^{2-}\right)$ : In a $8 \mathrm{~mm}$ diameter crystallization tube, upon slow diffusion through a ethanol layer $(1 \mathrm{~mL})$ of an aqueous solution $(1 \mathrm{~mL})$ of $1-2 \mathrm{H}^{+}, 2 \mathrm{Cl}-(6.2 \mathrm{mg}, 0.0195$ $\mathrm{mmol})$ into an aqueous solution $(1 \mathrm{~mL})$ of $\mathrm{K}_{2}\left[\mathrm{Hg}(\mathrm{SCN})_{4}\right](10$ $\mathrm{mg}, \quad 0.0195 \mathrm{mmol}), \quad$ colourless single-crystals ${ }_{70}\left(\left[\mathrm{Hg}(\mathrm{SCN})_{4}\right]\left[\mathrm{C}_{14} \mathrm{H}_{20} \mathrm{~N}_{4}\right]\right)$ were obtained at room temperature after several days in quantitative yield. Anal. Calcd. for $\mathrm{C}_{18} \mathrm{H}_{20} \mathrm{HgN}_{8} \mathrm{~S}_{4}$ : C, 31.89; H, 2.95; N, 16.53\%. Found: C, 29.77; H, 2.93; N, 16.67\%. IR data (KBr/pellet, $\left.\mathrm{cm}^{-1}\right): 3190$, 3027, 2096, 1651, 1617, 1557, 1470, 1371, 1311, 1186, 801, 75684 and 510 .

$\left(1-2 \mathrm{H}^{+}, \quad\left[\mathrm{Cu}(\mathrm{NCS})_{4}\right]^{2-}\right)$ : An aqueous solution $(2 \mathrm{~mL})$ of $\mathrm{Cu}\left(\mathrm{NO}_{3}\right)_{2} \cdot 3 \mathrm{H}_{2} \mathrm{O}(10 \mathrm{mg}, 0.041 \mathrm{mmol}$, was added to an aqueous solution $(2 \mathrm{~mL})$ of $\mathrm{NH}_{4} \mathrm{NCS}(6.3 \mathrm{mg}, 0.082 \mathrm{mmol})$ 80 and the mixture was stirred at $50{ }^{\circ} \mathrm{C}$. A EtOH $(3 \mathrm{~mL})$ solution of $1-2 \mathrm{H}^{+}, 2 \mathrm{Cl}^{-}(13.1 \mathrm{mg}, 0.041 \mathrm{mmol})$ was stirred at $50{ }^{\circ} \mathrm{C}$ before it was allowed to cool to room temperature. The latter was gently layered on top of the solution containing $\mathrm{Cu}\left(\mathrm{NO}_{3}\right)_{2} \cdot 3 \mathrm{H}_{2} \mathrm{O}$ and $\mathrm{NH}_{4} \mathrm{NCS}$. Upon slow evaporation at 85 room temperature, green single crystals of following formula $\left[\mathrm{Cu}(\mathrm{NCS})_{4}\right]\left[\mathrm{C}_{14} \mathrm{H}_{20} \mathrm{~N}_{4}\right]$ were obtained after several days in quantitative yield. Anal.: Calcd. for $\mathrm{C}_{18} \mathrm{H}_{20} \mathrm{CuN}_{8} \mathrm{~S}_{4}$ : C, 39.98; H, 3.70; N, 20.73\%. Found: C, 37.46; H, 3.77; N, 20.83\%. IR data $\left(\mathrm{KBr} /\right.$ pellet, $\left.\mathrm{cm}^{-1}\right): 3440,3185,3144,3036,2105,1652$, $901613,1555,1457,1362,1304,1196,854,756$ and 501.

\section{X-Ray Crystallography}

Data were collected at 173(2) K on a Bruker APEX8 CCD Diffractometer equipped with an Oxford Cryosystem liquid N2 device, using graphite-monochromated Mo-K $\alpha(\lambda=$ 95 0.71073) radiation. For all structures, diffraction data were corrected for absorption. The structures were solved using SHELXS-97 and refined by full matrix least-squares on $F^{2}$ using SHELXL-97. The hydrogen atoms were introduced at calculated positions and not refined (riding model). ${ }^{16} \mathrm{CCDC}$ 100 663025-663027 contains the supplementary crystallographic data for this paper. These data can be obtained free of charge 
at www.ccdc.cam.ac.uk/conts/retrieving.html or from the Cambridge Crystallographic data Centre, 12 Union Road, Cambridge CB2 1EZ, UK; Fax: (Internat.) +44-1223/336-033; E-mail: deposit@ccdc.cam.ac.uk.

${ }_{5}$ Crystallographic data for $\left(1-2 H^{+}, \quad\left[\operatorname{Pd}(\mathrm{SCN})_{4}\right]^{2-}\right)$ : $\mathrm{C}_{18} \mathrm{H}_{20} \mathrm{~N}_{8} \mathrm{PdS}_{4}, \mathrm{M}=583.06$, Triclinic, $a=7.1632(4) \AA, b=$ 12.3179(7) $\AA, c=13.0249(6) \AA, \alpha=94.640(2)^{\circ}, \beta=$ 96.935(2) $, \gamma=91.823(2)^{\circ}, U=1136.11(10) \AA^{3}$, Space group $P-1, \mathrm{Z}=2, \mu=1.208 \mathrm{~mm}^{-1}$, Refls measured : 29893, 10 Independent Refls: 6697, $R_{\text {int }}:$ 0.0287, Final $R$ indices $[\mathrm{I}>2 \operatorname{sigma}(\mathrm{I})]: R 1=0.0282, w R 2=0.0754, G O F=1.082$.

Crystallographic data for $\left(1-2 \mathrm{H}^{+}, \quad\left[\mathrm{Hg}(\mathrm{SCN})_{4}\right]^{2-}\right)$ : $\mathrm{C}_{18} \mathrm{H}_{20} \mathrm{HgN}_{8} \mathrm{~S}_{4}, \mathrm{M}=677.25$, Monoclinic, $a=7.18500(10) \AA$, $=12.6540(2) \AA, c=26.1910(6) \AA, \beta=95.7000(8)^{\circ}, U=$ $152369.49(7) \AA^{3}$, Space group $P 2_{l} / c, Z=4, \mu=6.871 \mathrm{~mm}^{-1}$, Refls measured : 12059, Independent Refls: 6889, $R_{\text {int }}$ : 0.0706, Final $\mathrm{R}$ indices $[\mathrm{I}>2 \operatorname{sigma}(\mathrm{I})]: \quad R l=0.0492$, $w R 2=0.0706, G O F=1.030$.

Crystallographic data for $\left(1-2 \mathrm{H}^{+}, \quad\left[\mathrm{Cu}(\mathrm{NCS})_{4}\right]^{2-}\right)$ : ${ }_{20} \mathrm{C}_{18} \mathrm{H}_{20} \mathrm{CuN}_{8} \mathrm{~S}_{4}, \mathrm{M}=540.20$, Monoclinic, $a=6.2310(2) \AA, b=$ 15.8090(4) $\AA, c=11.6190(4) \AA, \beta=96.7880(13)^{\circ}, U=$ 1136.52(6) $\AA^{3}$, Space group $P 2_{1} / c, Z=2, \mu=1.352 \mathrm{~mm}^{-1}$, Refls measured : 6064, Independent Refls : 3325, $R_{\text {int }}: 0.0205$, Final $\mathrm{R}$ indices $[\mathrm{I}>2 \operatorname{sigma}(\mathrm{I})]: R 1=0.0322, w R 2=0.0802$, ${ }_{25} G O F=1.014$.

\section{Acknowledgements}

This research was partly supported by a grant from the Ministry of Research and Technology to G. M. Thanks to Université Louis Pasteur, Institut Universitaire the France and ${ }_{30}$ CNRS for financial support.

\section{Notes and references}

\footnotetext{
${ }^{a}$ Institute of Physical Chemistry, Splaiul Independentei 202, 060021 Bucharest, Romania

$35{ }^{b}$ Inorganic Chemistry Laboratory, Faculty of Chemistry, University of Bucharest, Str. Dumbrava Rosie nr. 23, 020464 Bucharest, Romania ${ }^{C}$ Laboratoire de Chimie de Coordination Organique, UMR CNRS 7140, Université Louis Pasteur, Institut Le Bel, 4,rue Blaise Pascal, F-67000 Strasbourg, France, Fax: +33 390241325; Tel: +33 390241323; E-mail: 40 hosseini@.chimie.u-strasbg.fr
}

$\dagger$ Electronic Supplementary Information (ESI) available: [details of any supplementary information available should be included here]. See DOI: $10.1039 / \mathrm{b} 000000 \mathrm{x} /$

451 M. W. Hosseini, CrystEngComm., 2004, 6, 318.

2 M. Simard, D. Su, J. D. Wuest, J. Am. Chem. Soc., 1991, 113, 4696; S. Mann, Nature, 1993, 365, 499.

3 M. W. Hosseini, Acc. Chem. Res., 2005, 38, 313.

4 S. R. Batten and R. Robson, Angew. Chem. Int. Ed., 1998, 37, 1460; 50 B. Moulton and M. J. Zaworotko, Chem. Rev., 2001, 101, 1629; C. Janiak, Dalton Trans., 2003, 2781; M. W. Hosseini, in NATO ASI Series, Eds. D. Braga, F. Grepiono, G. Orpen, Serie C, Kluwer, Dordrecht, Netherlands, 1999, 538, 181; A. J. Blake, N. R. Champness, P. Hubberstey, W.-S. Li, M. A. Withersby and M. 55 Schröder, Coord. Chem. Rev.,1999, 193, 117; G. F. Swiegers and T. J. Malefetse, Chem. Rev., 2000, 100, 3483; M. Eddaoui, D.B. Moler, H. Li, B. Chen, T.M. Reineke, M. O'Keefe and O. M. Yaghi, Acc. Chem. Res., 2001, 34, 319; L. Carlucci, G. Ciani and D. M. Proserpio, Coord. Chem. Rev., 2003, 246, 247; S. Kitagawa, Angew. Chem. Int Ed., 2004, 43, 2434; G. Férey, C. Mellot-Draznieks, C. Serre and F. Millange, Acc. Chem. Res., 2005, 38, 218.

5 M. W. Hosseini, Coord. Chem. Rev., 2003, 240, 157.

6 S. Ferlay, O. Félix, M. W. Hosseini, J.-M. Planeix, N. Kyritsakas, Chem. Commun., 2002, 702; S. Ferlay, V. Bulach, O. Félix, M. W. 65 Hosseini, J.-M. Planeix, N. Kyritsakas, CrystEngComm, 2002, 4, 447. S. Ferlay, R. Holakovsky, M. W. Hosseini J.-M. Planeix, N. Kyritsakas, Chem. Commun., 2003, 1224; C. Paraschiv, S. Ferlay, M. W. Hosseini, V. Bulach, J-M. Planeix, Chem. Commun., 2004, 2270; S. Ferlay, M. W. Hosseini, Chem. Commun., 2004, 788; P. 70 Dechambenoit, S. Ferlay, M. W. Hosseini, Cryst. Gr. Des., 2005, 5, 2310; P. Dechambenoit, S. Ferlay, M. W. Hosseini, J.-M. Planeix, N. Kyritsakas, New. J. Chem., 2006, 30, 1403; E. F. Brès, S. Ferlay, P. Dechambenoit, H. Leroux, M. W. Hosseini, S. Reyntjens, J. Mater. Chem., 2007, 17, 1559.

757 J. C. M. Rivas and L. Brammer, Inorg. Chem., 1998, 37, 4756; L. Brammer, J. K. Swearingen, E. A. Bruton and P. Sherwood, Proc. Natl. Acad. Sci. USA, 2002, 99, 4956; L. Brammer, G. M. Espallargas and H. Adams, CrystEngComm, 2003, 5, 343; G. R. Lewis, A. G. Orpen, Chem. Commun., 1998, 1873; A. L. Gillon, A. G. Orpen, J. 80 Starbuck, X-M. Wang, Y. Rodriguez-Martin, C. Ruiz-Pérez, Chem. Commun., 1999, 2287; P. C. Crowford, A. L. Gillon, J. Green, A. G. Orpen, T. J. Podesta, S. V. Pritchard, Cryst. Eng. Comm., 2004, 419.

8 M. Felloni, P. Hubberstey, C. Wilson and M. Schröder, CrystEngComm, 2004, 6, 87; K. Kumar, A. Ballabh, D. A. Jose, P.

85 Dastidar and A. Das, Cryst. Growth Des., 2005, 5, 651; X. Ren, J. Xie, Y. Chen and R. K. Kremer, J. Mol. Struct., 2003, 660, 139; M. Fourmigué, C. Mézière and S. Dolou, Cryst. Growth Des., 2003, 3, 806; J. Valdés-Martinez, M. Del Rio-Ramirez, S. Hernandez, 
Ortega, C. B. Aakeröy and B. Helfrich, Cryst. Growth Des., 2001, 1, 485.

9 C. Paraschiv, S. Ferlay, M.W. Hosseini, N. Kyritsakas, J-M. Planeix and M. Andruh, Rev. Roum. Chim., 2007, 52, 101.

510 D. Vujovic, H. G. Raubenheimer, L. R. Nassimbeni, Dalton Trans., 2003, 631; D. Bose, S.H. Rahaman, G. Mostefa, H-K. Fun, R. D. B. Walsh, M. J. Zaworotko, B. K. Ghosh, Polyhedron, 2004, 23, 2045; P. C. Crawford, A. Gillon, J. Green, A. G. Orpen, T. Podesta, S. V. Pritchard, CrystEngComm, 2004, 6, 419; H.Y Bie, J. Lu, J-H Yu, J-Q

10 Xu, K. Zhao, X. Zhang, J. Sol. St. Chem., 2005, 178, 1445; D. Bose, J. Banerjee, S. H. Rahaman, R. Ghosh, G. Mostefa, J. Ribas, C-H. Hung, B. K. Ghosh, Polyhedron, 2006, 25, 645; M. Du, C-P. Li, X-J. Zhao, CrystEngComm, 2006, 8, 552; A. Cucos, N. Avarvari, M. Andruh, Y. Journaux, A. Müller, M. Schmidtmann, Eur. J. Inorg.

15 Chem., 2006, 903; R. Ghosh, A. D. Jana, S. Pal, G. Mostefa, H-K. Fun, B. K. Ghosh, CrystEngComm, 2007, 353.

11 R.G. Pearson, J. Am. Chem. Soc., 1963, 85, 3533; R.G. Pearson, Adv. Inorg. Chem. Radiochem., 1966, 8, 177; F. Basolo, Coord. Chem. Rev., 1968, 3, 213; J.L. Burmeister, Chem. Rev., 1968, 3, 225.

2012 O. Félix, M. W. Hosseini, A. De Cian, J. Fischer, New J. Chem., 1997, 21, 285.

13 Q.-M, Wang, X.-T. Wu, W.-J. Zhang, T.-L. Shang, P. Lin, J.-M. Li, Inorg. Chem., 1999, 38, 2223; (b) H-J. Chen, L-Z. Zhang, Z-G. Cai, G. Yang, X-M. Chen, Dalton Trans., 2000, 2463.

2514 A. Mawby, G. E. Pringle, J. Chem. Soc., Chem. Commun., 1970, 385; A. Mawby, G. E. Pringle, J. Inorg. Nucl. Chem., 1972, 34, 2213.

15 A. Rosenheim, R. Cohn, Z. Anorg. Allgem. Chem., 1901, 27, 285; Handbuch der Preparativen Anorganischen Chemie in drei Bänden, Herausgegebrn von Georg Brauer, ed. Ferdinand Enke, Vertag Stuttgart, 1978, vol. II, pp.1964.

16 G. M. Sheldrick, Programs for the Refinement of Crystal Structures, University of Göttingen, Göttengen, Germany, 1996. 


\section{Graphical abstract}

Upon combining the bisamidinium dication $1-2 \mathrm{H}^{+}$with thiocyanatometallates $\mathrm{M}(\mathrm{SCN}) 4^{2-}(\mathrm{M}=\mathrm{Pd}, \mathrm{Hg})$ or isothiocyanatometallates $\mathrm{Cu}(\mathrm{NCS}) 4^{2-}$ anions three new hybrid 1- and 2-D H bonded molecular networks respectively have been generated and structurally characterized by X-ray diffraction on single crystals. 